\title{
Deoxyribonucleic Acid Homologies Among Acid-Producing Strains of Rhizobium
}

\author{
V. L. CROW, ${ }^{1}$ B. D. W. JARVIS, ${ }^{1}$ AND R. M. GREENWOOD ${ }^{2}$ \\ Department of Microbiology and Genetics, Massey University, Palmerston North, New Zealand ${ }^{1}$ and \\ Applied Biochemistry Division, Department of Scientific and Industrial Research, \\ Palmerston North, New Zealand ${ }^{2}$
}

Plant specificities and deoxyribonucleic acid homologies were studied among 122 strains of Rhizobium. Some strains were assigned to species on the basis of their source of isolation and present nodulation capabilities, but many did not fit into one of the six currently recognized species of the genus Rhizobium. Among those strains assigned to species were many which also nodulated plants outside their species-specific, cross-inoculation group. Conversely, isolates from a wide variety of plants could be designated Rhizobium phaseoli since they were capable of nodulating Phaseolus vulgaris. Acid production and growth rate on yeastmannitol agar were tested for all strains. Some strains grew rapidly but did not produce an acid reaction; these were grouped with the fast growing acid producers. Deoxyribonucleic acid homology was used to identify four genetic groups of fastgrowing, acid-producing rhizobia. Group 1 included strains of Rhizobium trifolii (except strains obtained from Trifolium lupinaster), Rhizobium leguminosarum, Rhizobium phaseoli (obtained from Phaseolus vulgaris), and two strains obtained from Neptunia gracilis. Group 2 comprised six American strains obtained from crown vetch (Coronilla varia), sainfoin (Onobrychis vicifolia), and Sophora spp. Species status for this group should remain tentative until further strains have been studied. Group 3 corresponded with Rhizobium meliloti as presently defined. Group 4 included fast-growing Lotus rhizobia, two strains obtained from $T$. lupinaster, and a wide variety of previously unclassified strains. Nine fastgrowing strains could not be included in any of these groups. The nine slowgrowing, non-acid producing strains included in this study showed $<10 \%$ homology with DNAs from seven fast-growing reference strains. The relationships between subgroups in group 1 are discussed, and the genetic diversity of strains obtained from Phaseolus vulgaris is examined. It is proposed that fast-growing rhizobia comprise at least four species corresponding with the four genetic groups described.

The classification of legume root-nodule bacteria presented in the 8th edition of Bergey's Manual of Determinative Bacteriology (18) places them in one genus, that of Rhizobium. This genus is divided into two groups distinguished by differences in growth rate, carbohydrate utilization, and flagellation. The six species of rhizobia described are distinguished by the leguminous plants they nodulate. The unsatisfactory aspects of this species classification have been reviewed previously $(6,15)$.

Deoxyribonucleic acid (DNA) reassociation has been used to study the relationships between fast-growing, acid-producing rhizobia and agrobacteria $(7,12)$ and between root-nodule bacteria from legumes indigenous to New Zealand and strains designated as Rhizobium lupini (16). Recently, Jarvis et al. (15) used this technique to determine DNA homologies among 27 strains of Rhizobium trifolii, 4 strains of Rhizobium leguminosarum, and 4 strains of Rhizobium phaseoli. It was proposed that Rhizobium trifolii and Rhizobium leguminosarum should be combined under the name which has priority: Rhizobium leguminosarum Frank. Two Rhizobium strains obtained from African Trifolium species and two obtained from a northern Asiatic species were less closely related. The average relatedness of Rhizobium strains taken from Phaseolus vulgaris to those obtained from clover was $46 \%$, but the authors suggested that Rhizobium phaseoli should be retained at present as a separate species and examined in more detail.

This paper describes the DNA homologies among 113 strains of fast-growing, acid-producing rhizobia and seven reference DNAs from Rhizobium spp. Nine slow-growing, non-acidproducing strains have been included for comparative purposes. 


\section{MATERIALS AND METHODS}

Bacterial strains. The bacterial strains included in this investigation are listed in Table 1 together with their hosts of isolation and countries of origin. The strains are arranged in groups which correspond with the DNA homology groups in Table 2. The fast-growing rhizobia are divided into five groups and the slowgrowing rhizobia form a sixth group. Within each group, all strains are alphabetically ordered according to plant host. In addition, the group 1 Rhizobium strains from clovers are organized according to geographic origin.

Cultural methods. The media and methods of culture maintenance we used have been described in a previous communication (15). Acid production was determined on yeast extract-mannitol agar by the method of Norris (22). Growth rate was measured by following the increase in turbidity during log-phase growth of cultures in yeast extract-glucose media (19). Strains with generation times of $<5 \mathrm{~h}$ were designated fast-growing and those with generation times $>5 \mathrm{~h}$, as slow-growing.

Nodulation and effectiveness. The method described by Jarvis et al. (15) was used to determine nodulation and effectiveness of nodulation.

Genome size measurement. The spectrophotometric method of De Ley et al. (4) was used to determine genome size. A UNICAM SP 1800 ultraviolet spectrophotometer with SP876 series 2 temperatureprogram controller (Pye Unicam Ltd., Cambridge, England) set at $76^{\circ} \mathrm{C}$ and fitted with a Perkin-Elmer model 56 recorder (Perkin-Elmer, Norwark, Conn.) was used. The genome size was calculated by using the equation of Gillis et al. (8) and reference Escherichia coli DNA (3.28 × $10^{9}$ daltons; De Ley [3]).

DNA preparation and reassociation experiments. The preparation of unlabeled DNA and DNA labeled with ${ }^{32} \mathrm{P}$, the DNA reassociation technique with the batch hydroxyapatite procedure to separate unreassociated from reassociated DNA, and the regeneration of hydroxyapatite were as described by Jarvis et al. (15) except for two modifications. In the preparation of labeled DNA, the step after sonication for 56 $s$, in which the labeled DNA was denatured and then eluted from an hydroxyapatite column, was omitted. The purity and hybridization values obtained with labeled DNA prepared in this way were independent of this step. Secondly, samples of reassociated DNA were frozen at $-20^{\circ} \mathrm{C}$ for up to $48 \mathrm{~h}$ before being thawed and analyzed by batchwise elution from hydroxyapatite. The hybridization values were unaffected by storage under these conditions.

\section{RESULTS}

Acid production and growth rate. Most strains were classified as fast-growing acid producers on the basis of colony size and marked acid production on yeast extract-mannitol agar. The following strains (with the plant from which they were obtained within parentheses) showed little or no acid production, but on the basis of colony size, generation time, and host range, they were classified as fast growers: strains NZP5469 (Lathyrus sativus), 63 (Pisum arvense), CB1170 (Medicago sativa), CC1005 (Hosackia sp.), 461 (Lotus sp.), NZP5302 (Robinia pseudoacacia), CB81 (Leucaena leucocephala), J1070 (Mimosa invisa), and X18b (Mimosa caesalpiniaefolia).

Only the following strains (with the plants from which they were obtained within parentheses) were classified as slow-growing, nonacid producers: ES1 (Erythrina speciosa), NZP2192 and NZP2257 (Lotus corniculatus), NZP2076 (Lotus suaveoleus), NZP5087 (Lupinus angustifolius), WU425 (Ornithopus compressus), NZP5113 (Ornithopus perpusillus), 94 (Phaseolus acutifolius), and 100 (Phaseolus aureus).

Homology and plant specificity. The plant specificities of the various Rhizobium strains that we used in this investigation are listed in Table 1. Selected strains of Rhizobium trifolii, Rhizobium leguminosarum, Rhizobium phaseoli, and Rhizobium meliloti were tested on a wide variety of hosts, and the results indicate that strains which fit into the classification scheme of Bergey's Manual of Determinate Bacteriology on the basis of plant origin or nodulating capacity may also nodulate a variety of other hosts which are not formally included in their species-specific, cross-inoculation groups; many of the remaining strains did not fall into any of the six currently recognized species in the genus Rhizobium (18).

Rhizobia obtained from Trifolium polymorphum (NU125), Trifolium repens (CC275e), Phaseolus vulgaris (NZP5459), Lotus corniculatus (CC811), Lotus maroccanus (CC809a), Coronilla varia (CC401), and Medicago sativa (SU47) were used to provide labeled reference DNAs. These reference DNAs were reassociated with unlabeled DNA from up to 122 strains of rhizobia and with DNA from Escherichia coli $\mathrm{K}-12$. The relative homology values were used to organize the strains into groups showing similar genetic homologies, and these are listed in Table 2.

Genetic homology in group 1. The common features of the 64 strains in group 1 were the high mean homology values of 51,65 , and $54 \%$ with reference DNAs from NU125, CC275e, and NZP5459, respectively, and the low mean homology values of $7,9,23$, and $14 \%$ with reference strains CC811, CC809a, CC401, and SU47, respectively. The geographic and plant origins of these strains were diverse. Thirty-one $R h i$ zobium trifolii strains originated from 16 clover (Trifolium) species, 16 Rhizobium leguminosarum strains orignated from various Pisum, Vicia, and Lathyrus species, 13 Rhizobium phas- 


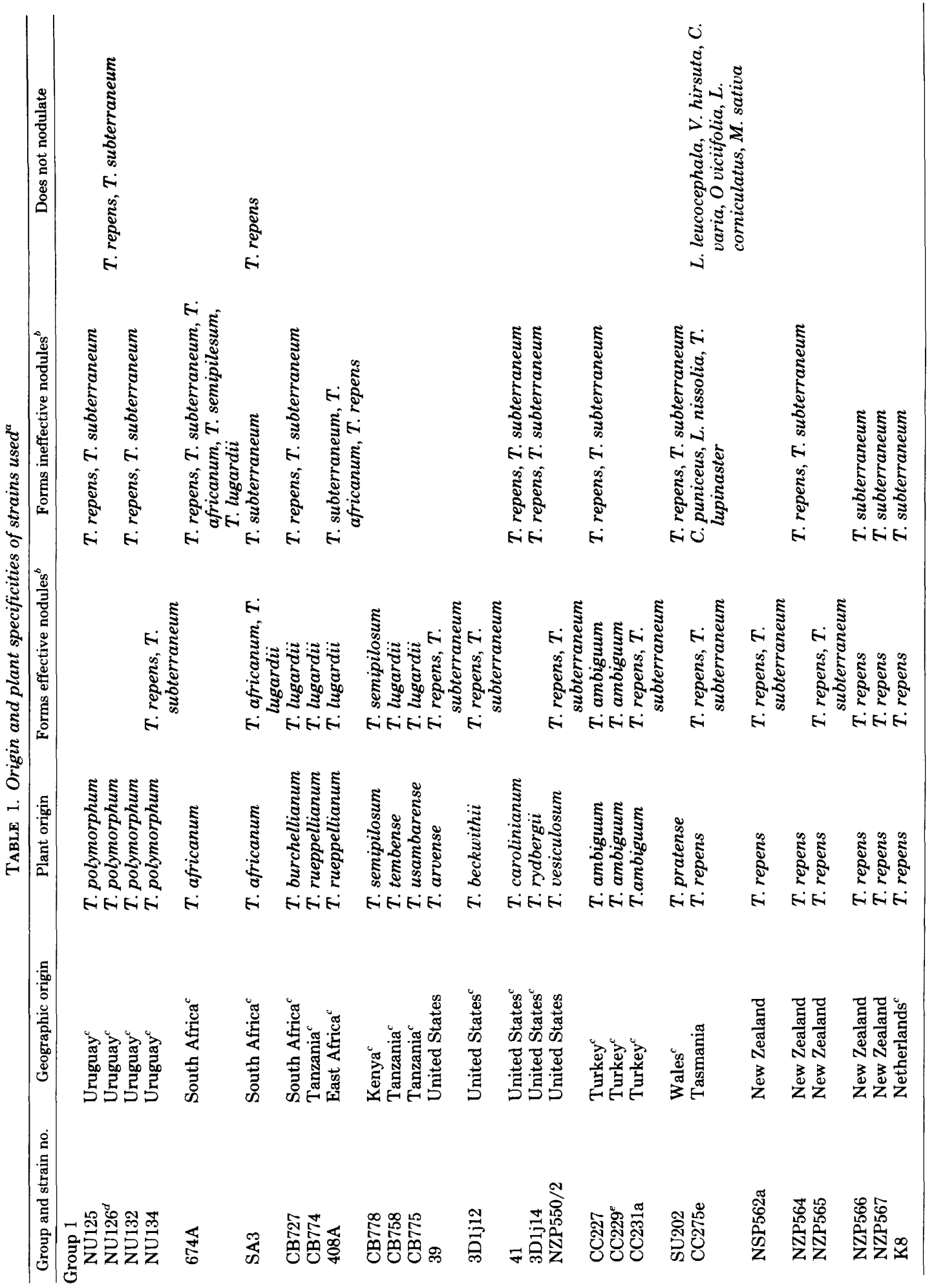




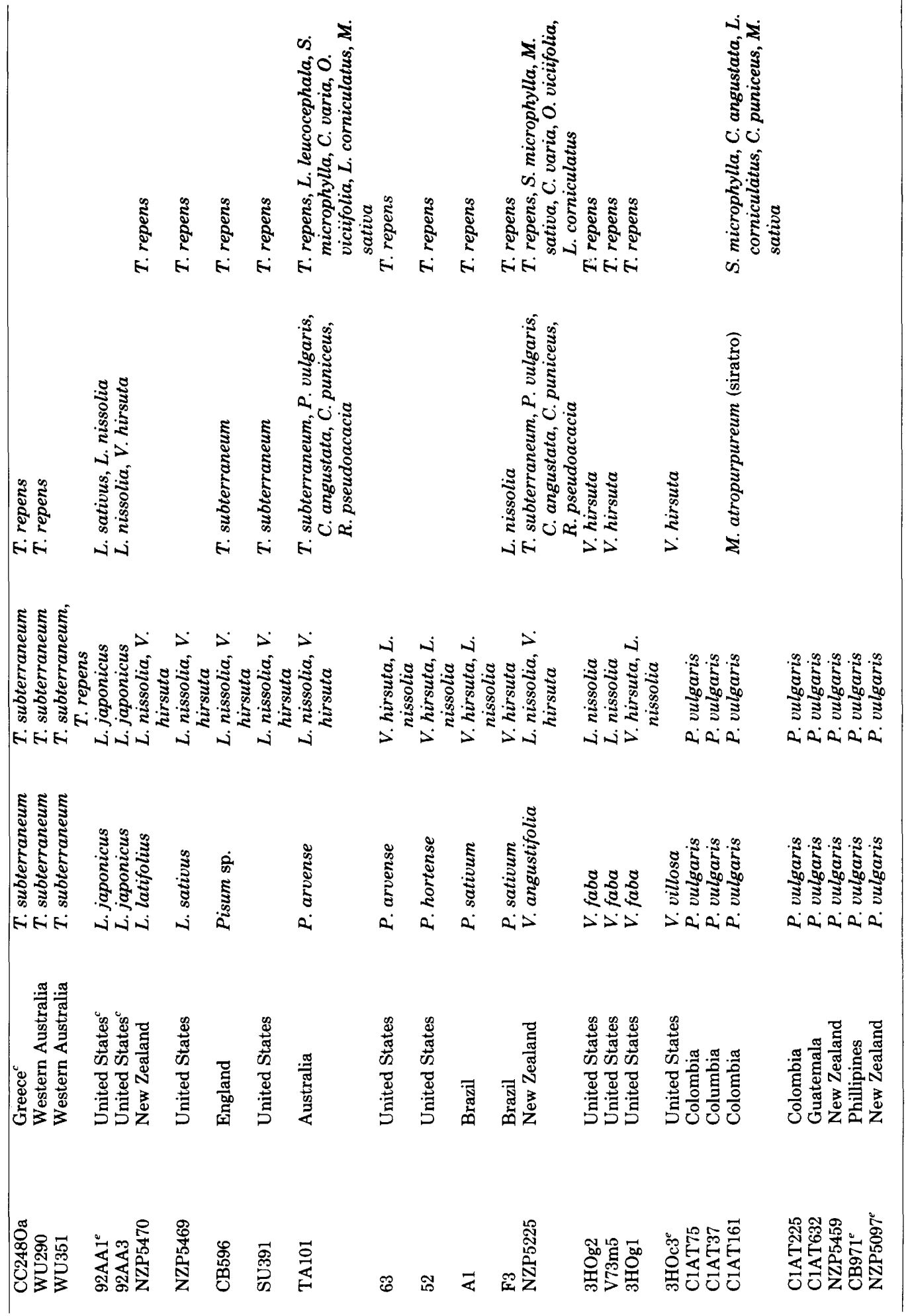




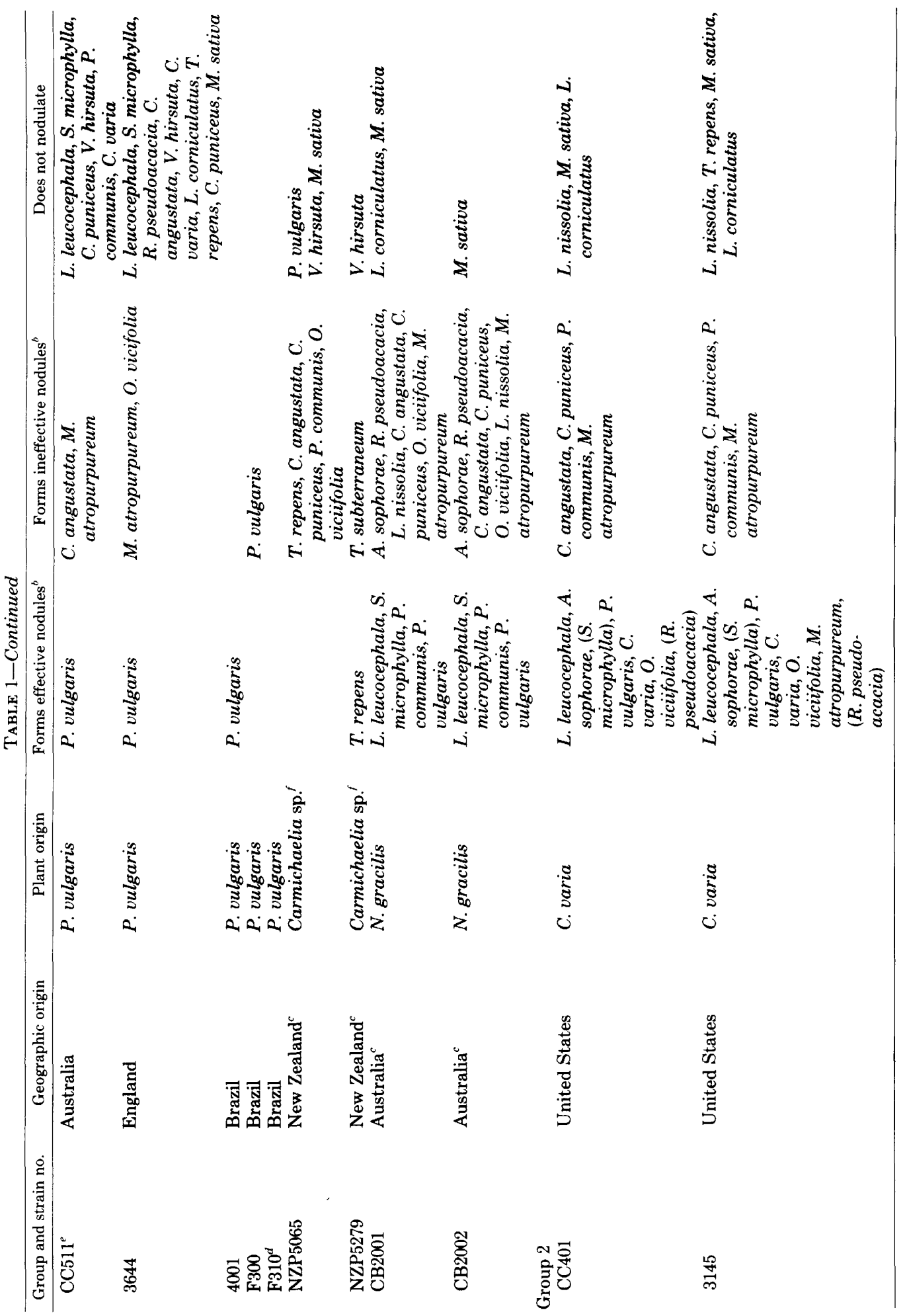




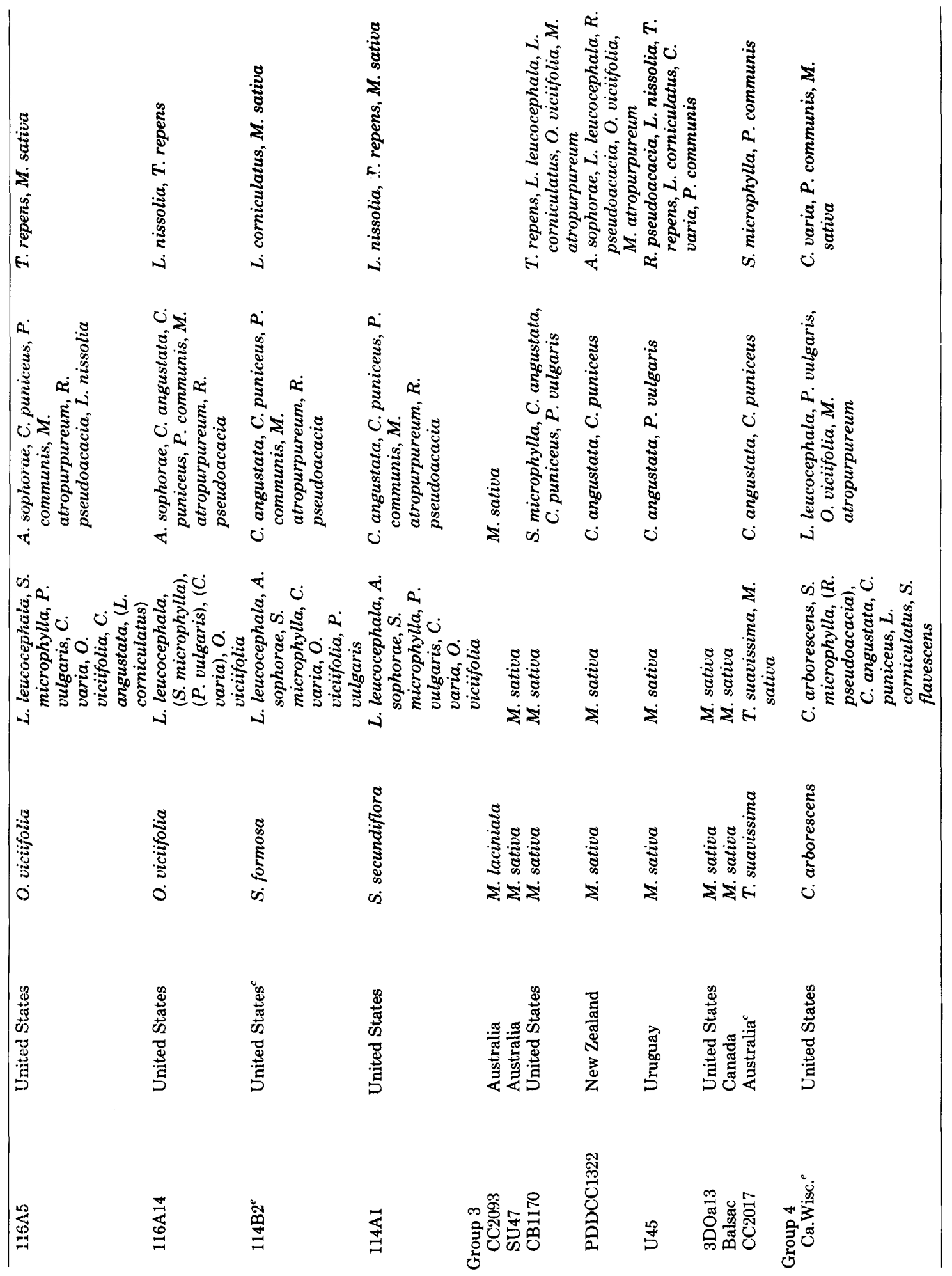




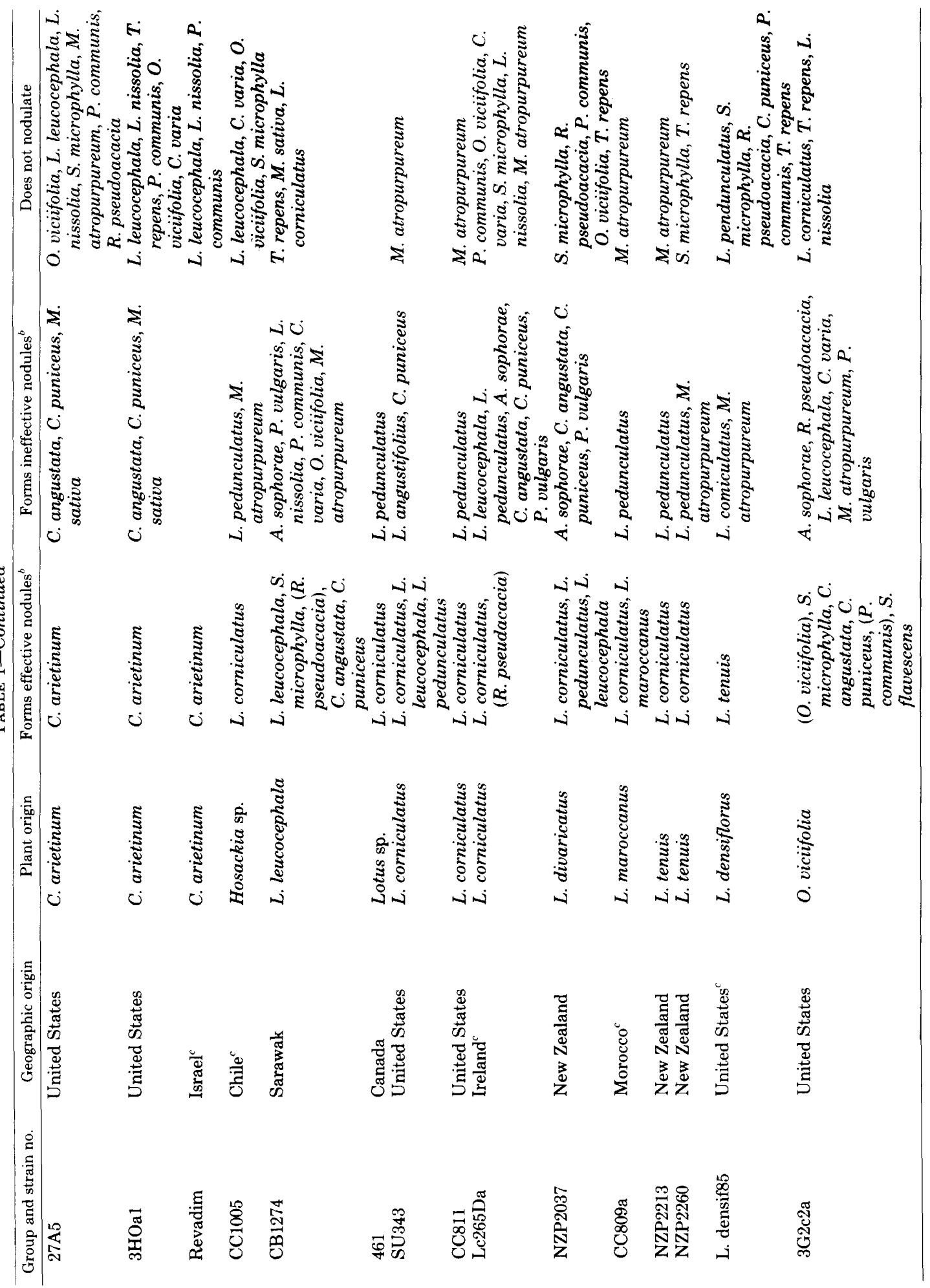




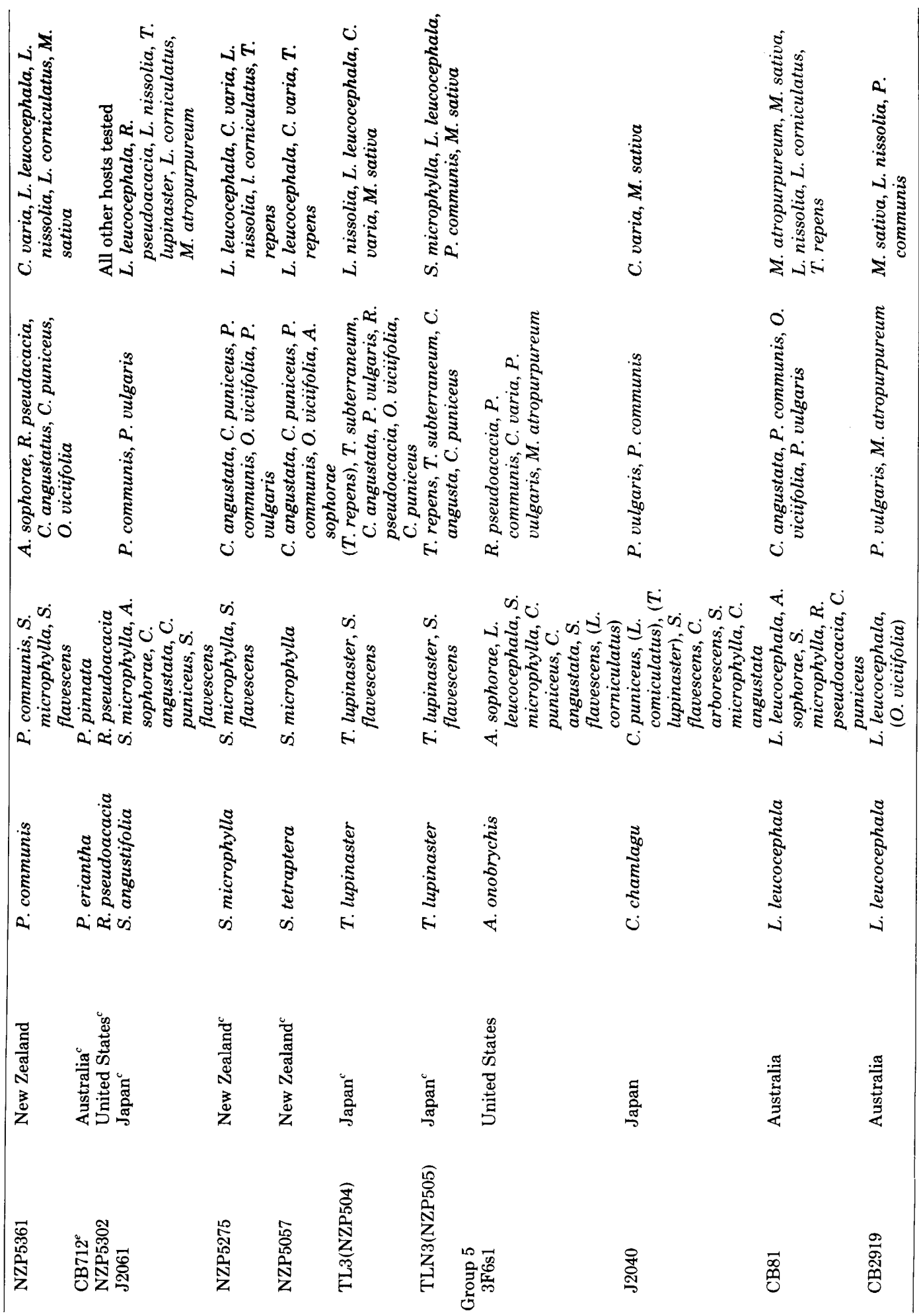



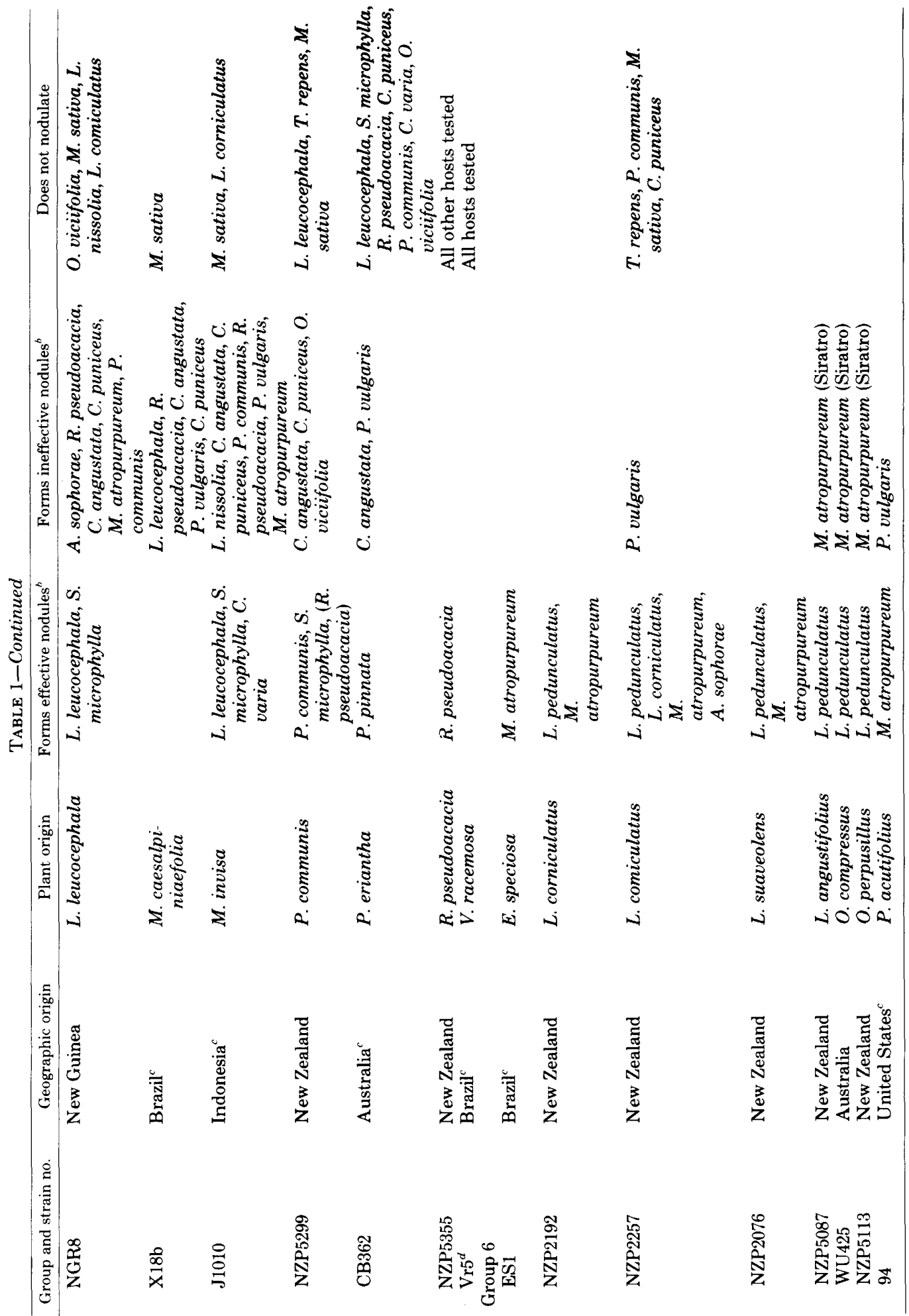


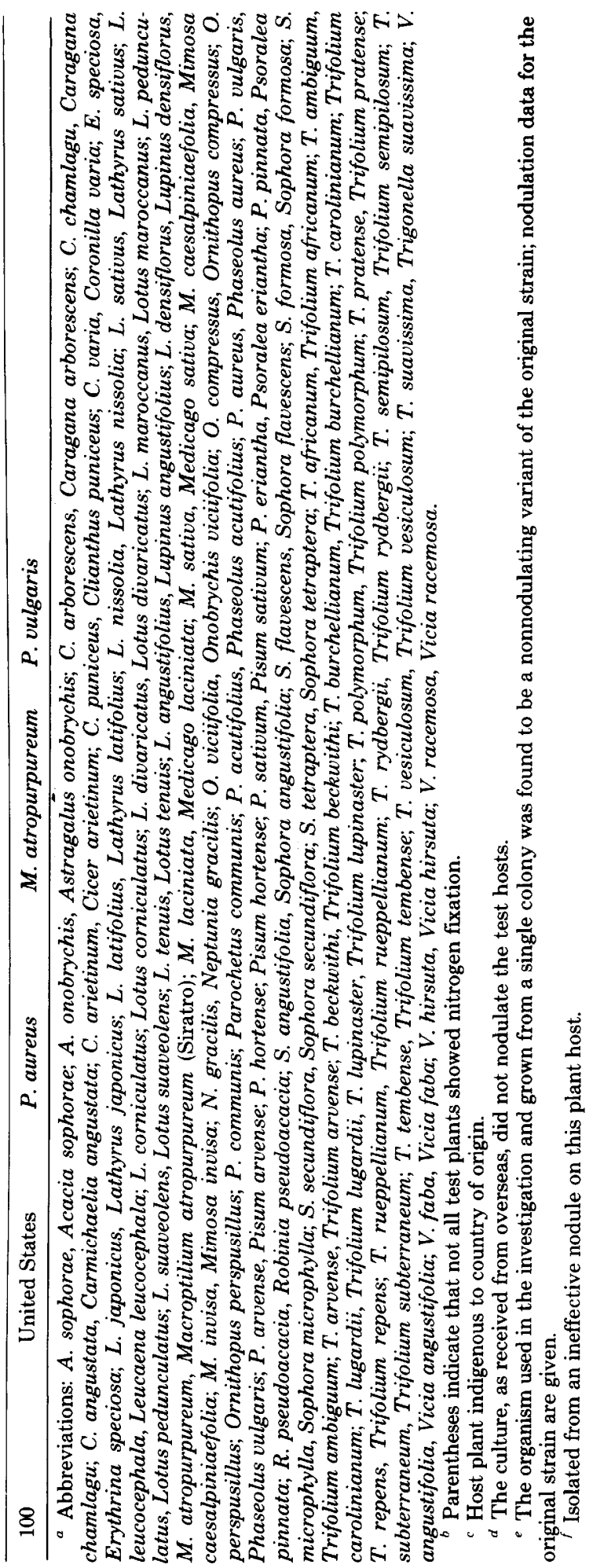




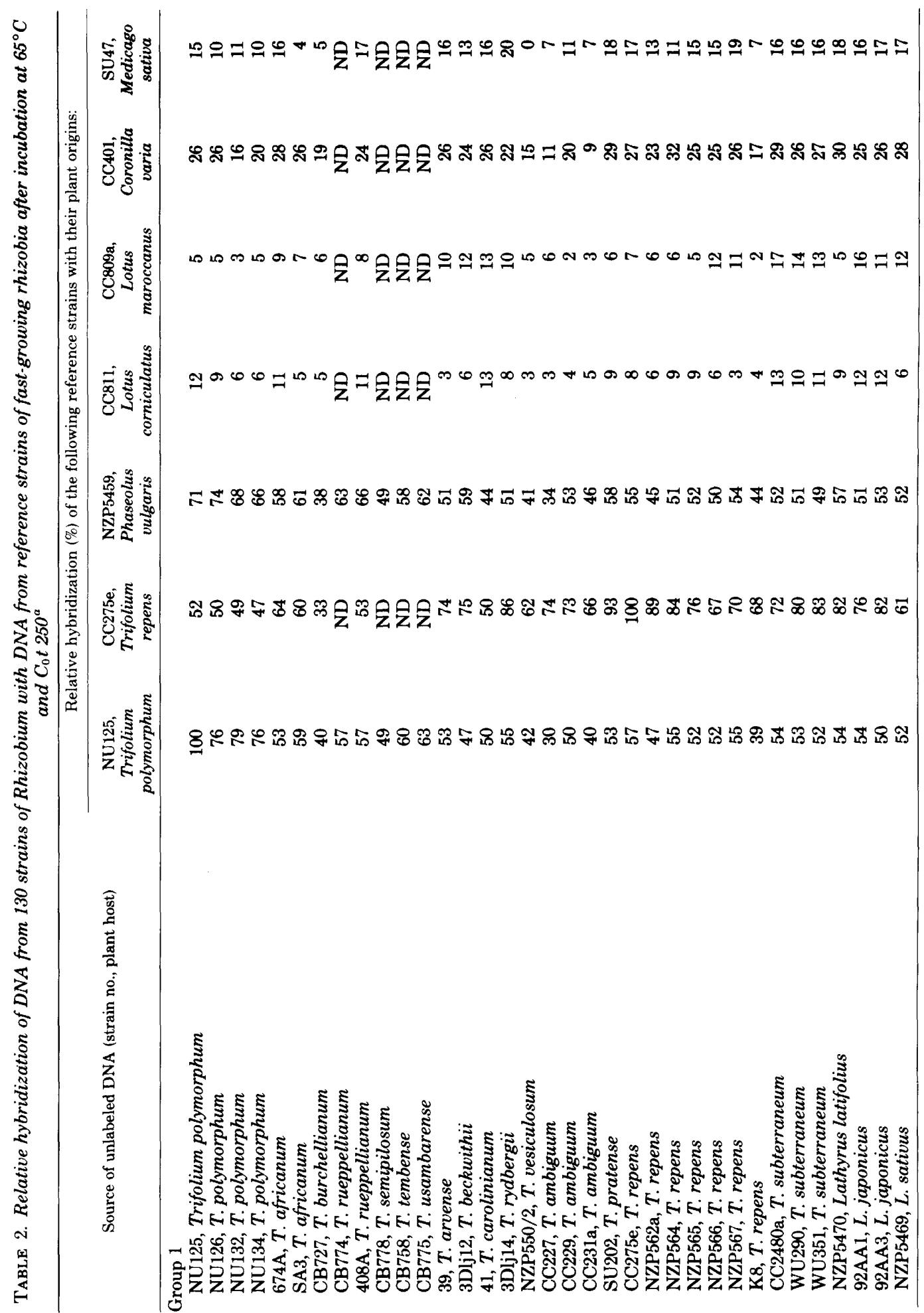



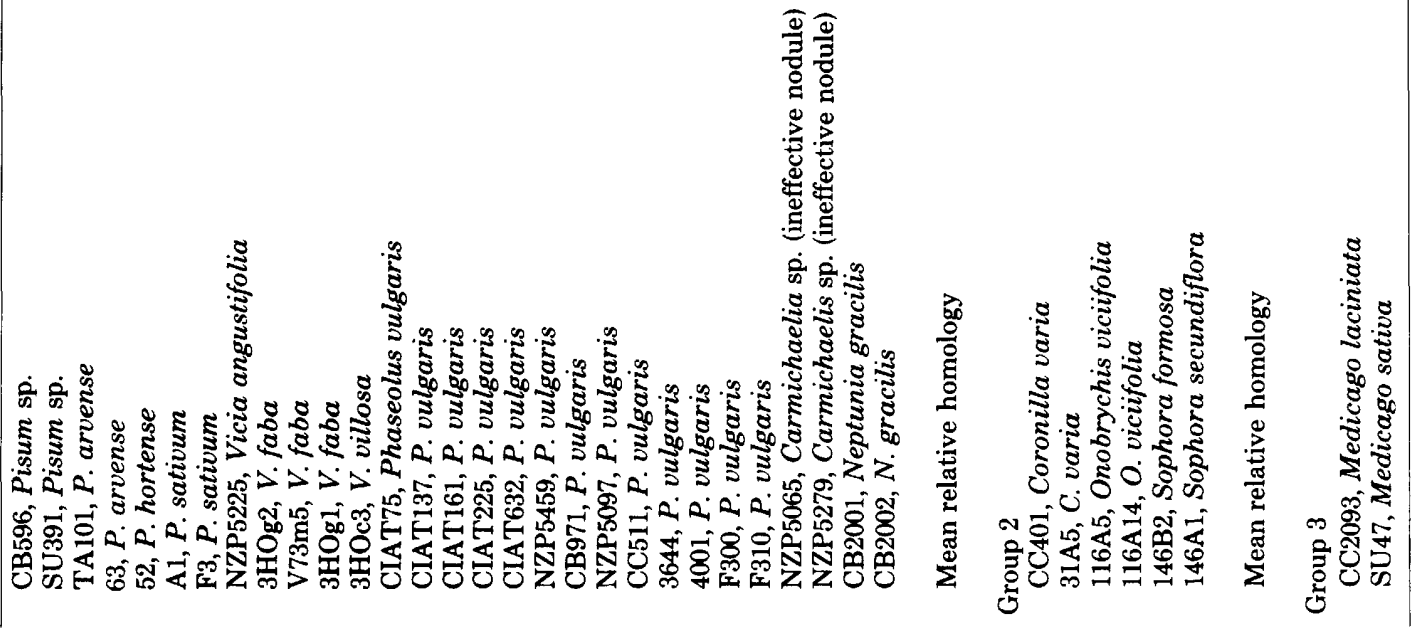


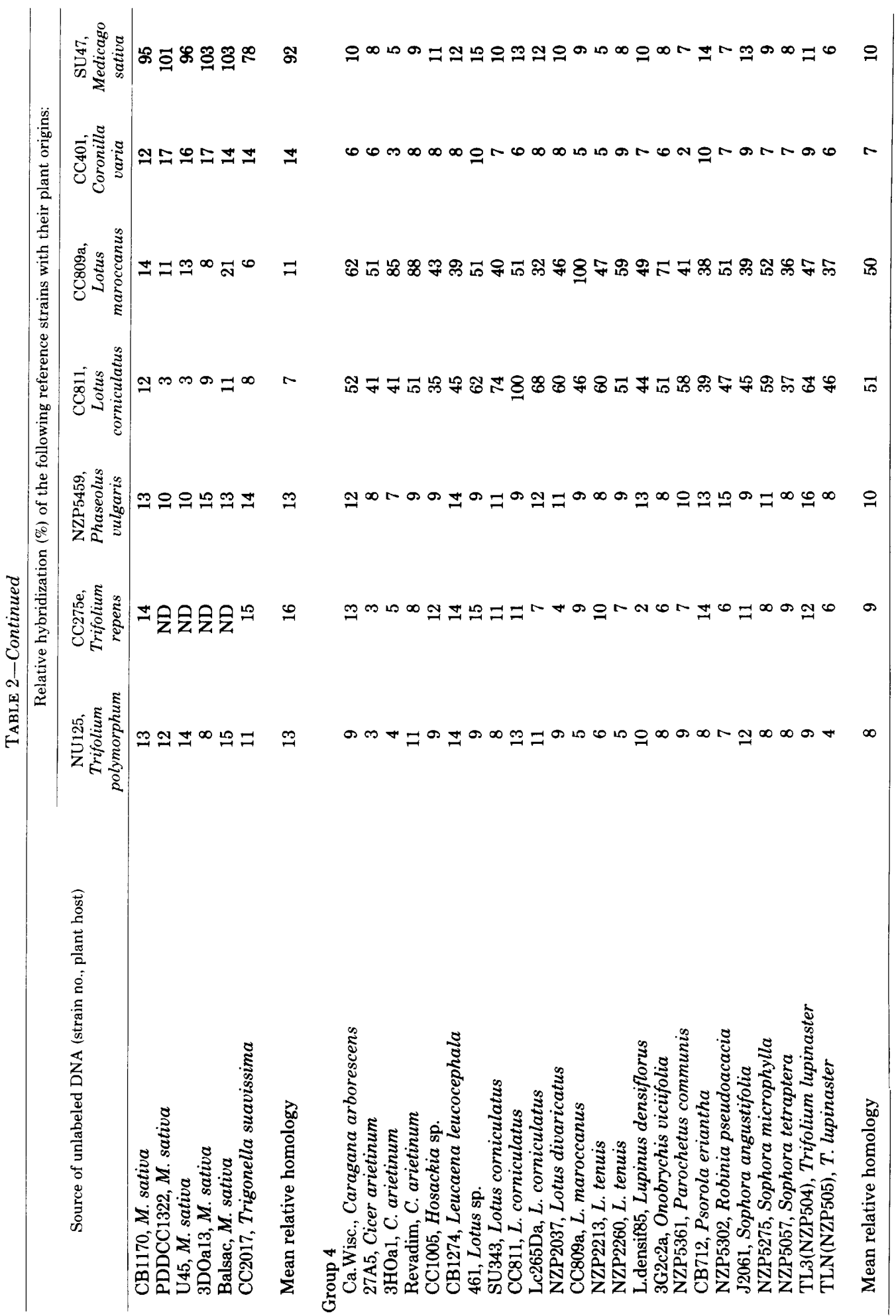




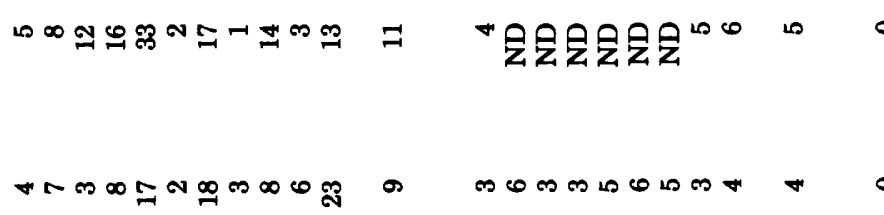
ind

ลัง ำ

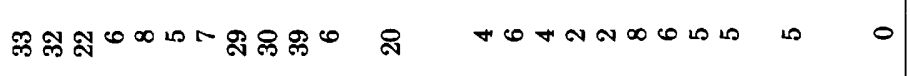

ம

NOFம

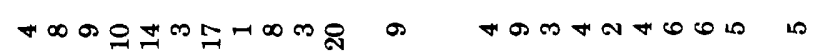
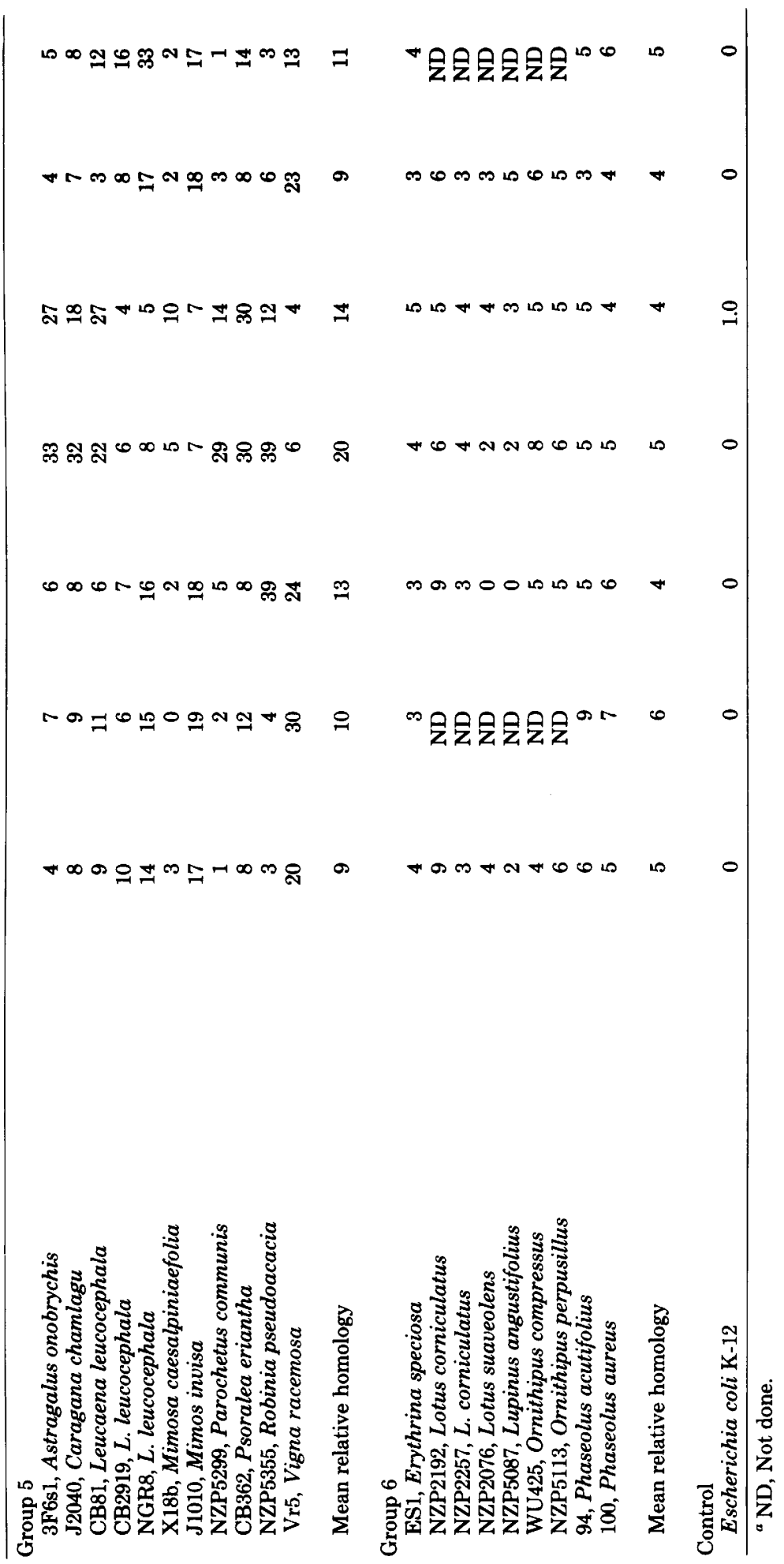
eoli strains originated from bean (Phaseolus vulgaris) species, and 2 Rhizobium strains each originated from Carmichaelia sp. and 2 from Neptunia gracilis.

Genetic diversity and plant specificity in group 1. As seen in Table 2, there was considerable genetic diversity within the group. The calculation of mean homology values for strains from the same plant host or geographic location indicated that some subgroups existed. For example, the mean homology values of clover rhizobia with respect to the reference DNA from NU125, CC275e, and NZP5459 were 83, 50, 70\%, respectively, for the 4 Trifolium polymorphum strains, 55,53 , and $57 \%$, respectively, for the 3 African Trifolium strains (674A through CB775), and 49, 78, and 50\%, respectively, for the remaining 19 strains from European, Caucasian, and North American Trifolium species.

The mean homologies for rhizobia from European, Caucasian, and North American clovers were very similar to those for pea rhizobia $(50$, $71,53 \%$, respectively) and indicated that plant specificity among clover and pea rhizobia was not reflected in base-sequence homology.

Strains designated Rhizobium phaseoli showed some base sequence divergence from Rhizobium trifolii and Rhizobium leguminosarum and a lower average homology with reference DNA from Rhizobium phaseoli NZP5459 than did Rhizobium trifolii or Rhizobium leguminosarum strains with reference DNA from Rhizobium trifolii strain CC275e. Four strains of Rhizobium from Trifolium polymorphum showed a higher mean homology $(70 \%)$ with reference DNA from Rhizobium phaseoli NZP5459 than did other bean rhizobia $(58 \%)$. However, when a strain of Rhizobium from Trifolium polymorphum (NU125) was used to provide reference DNA, the average homology with Rhizobium phaseoli strains was only $49 \%$, and the range was 24 to $68 \%$. These results indicate that although some strains of Rhizobium from clover and beans have considerable base-sequence homology, strains designated Rhizobium phaseoli are a genetically diverse group which contains members which are not closely related to Rhizobium trifolii and Rhizobium leguminosarum.

The two Rhizobium strains from Carmichaelia were obtained from ineffective nodules on Carmichaelia flagelliformis seedlings used as trap hosts for isolating rhizobia from soil samples. Both strains behaved as clover rhizobia, nodulating clover species freely, and strain NZP5279 fixed nitrogen on white clover. In contrast, rhizobia effective on Carmichaelia spp. did not nodulate clovers (11) and showed low DNA homology with Rhizobium trifolii (16).
The DNA homology of the two strains (Table 2) confirms that the strains are members of $R h i$ zobium trifolii.

The two strains of rhizobia from Neptunia gracilis had homology values within the range for the clover, pea, and bean rhizobia. The inclusion of these two strains in group 1 was not expected on the basis of plant specificity. Although they both fixed some nitrogen on Phaseolus vulgaris and nodulated Lathyrus nissolia, in most respects they were quite distinct in host range from other strains in group 1 . Thus, none of the Rhizobium leguminosarum, Rhizobium phaseoli, or Rhizobium trifolii strains that were tested nodulated Leucaena leucocephala or fixed nitrogen with Sophora microphylla or Parochetus communis.

Two strains included in group 1 showed comparatively low homology with reference strains NU125, CC275e, and NZP5459. Strain CB727, from Trifolium burchellianum, showed host specificity typical of strains obtained from African clovers. It could fix some nitrogen on Trifolium lugardii, and it also nodulated white and subterranean clovers. Strain F300, on the other hand, although received as a strain of Rhizobium phaseoli, was found to nodulate Phaseolus vulgaris but not to fix nitrogen on this host. There is, therefore some doubt whether F300 should be regarded as a typical Rhizobium phaseoli strain.

The DNA homology values for F300 support this as the values are $33 \%$ or less with the three group 1 reference strains (NU125, CC275e, and NZP5459). However, this strain showed less homology with the other four reference strains and, therefore, is placed in the group 1 homology grouping because, traditionally, this strain would be called Rhizobium phaseoli. Further study, however, may result in this strain being grouped with some of the strains from group 5.

A wide range of Rhizobium strains is able to nodulate Phaseolus vulgaris (14), including, as determined in the investigation reported here, strains from several different homology groups given in Tables 1 and 2 .

Genetic homology in group 2. The six strains in group 2 (Table 2) formed a distinct genetic cluster which had a mean homology of 96\% (range 78 to 106 ) with reference DNA from strain CC401 isolated from Coronilla varia. They showed low DNA homology (18 to 30\%) with reference DNAs from NU125, CC175e, and NZP5459, and very little homology (0 to $9 \%)$ with reference DNAs from CC811 and CC809a. The six strains were isolated in the United States from four hosts, two of them indigenous to North America and two naturalized in the United States but originally from Europe. Nevertheless, 
all of the six Rhizobium strains were closely similar in plant specificity. They all fixed nitrogen with Leucaena leucocephala, Sophora microphylla, Phaseolus vulgaris, Coronilla varia, and Onobrychis vicifolia; no other strains used in this investigation formed effective nodules on all five species. They did, however, differ among themselves in nodulation and nitrogen fixation with certain other hosts (e.g. Acacia sophorae, Macroptilium atropurpureum (Siratro), and Lathyrus nissolia), as indicated in Table 1.

Genetic homology and plant specificity in group 3. Only strains belonging to the alfalfa cross-inoculation group (Rhizobium meliloti) were found in group 3 . These strains showed a range of homology values of from 68 to $103 \%$ with DNA from the alfalfa reference strain SU47, and little homology (3 to 17\%) with other reference DNAs. Six of the strains showed a homology of $95 \%$ or greater with SU47 reference DNA. The remaining two strains, which showed $68 \%$ and $78 \%$ homology, were isolated from $\mathrm{Med}$. icago laciniata and Trigonella sauvissima, species with very specific rhizobial requirements (1). Rhizobia not belonging to the alfalfa crossinoculation group showed low homology with respect to the SU47 reference DNA (0 to 19\%) except for NGR8 (group 5), a strain from Leucaena leucocephala, which showed $33 \%$ homology. Although in this investigation no symbiotic relationship was found between Medicago sativa and Leucaena leucocephala rhizobia, Trinick (25) reported that some strains from Leucaena leucocephala, but not NGR8, were able to form ineffective nodules on Medicago sativa.

Genetic homology in group 4 . The strains placed in group 4 showed relatively high mean DNA homologies (51 and 50\%) with the two reference strains CC811 and CC809a from Lotus spp. and low homologies (7 to $10 \%$ ) with DNAs from the other reference strains. Group 4 is genetically diverse, since homology values with reference DNAs from Lotus rhizobia ranged from 36 to $88 \%$. Two Rhizobium strains, TL3 and TLN3 from Trifolium lupinaster, would be classified as Rhizobium trifolii on the basis of their plant origins and cross-inoculation groups; the remainder have not been previously classified.

The six strains associated with Lotus corniculatus and Lotus tenuis had a mean homology of $63 \%$ relative to strain CC811 from Lotus corniculatus a value appreciably higher than the mean of $48 \%$ for the remaining strains of group 4. The mean homology of the same six strains relative to strain $\mathrm{CC} 809 \mathrm{a}$ from a different Lotus species was $47 \%$ compared with $51 \%$ for the remaining group 4 strains. These results suggest that a distinguishable subgroup may be associ- ated with Lotus corniculatus and Lotus tenuis. These are closely related plant species.

Plant specificity in group 4. Group 4 strains were isolated from many different hosts, with species from 12 genera, and they were also of diverse geographic origin. They differed greatly in host specificity, including the range of hosts that they could nodulate. Thus, strain NZP5302 (obtained from an American peat culture for Robinia pseudoacacia) was not found to nodulate any legumes other than Robinia pseudoacacia, but strains CaWisc, CB1274, and 3G2c2a could fix nitrogen with five or more unrelated legumes, and nodulate many others. On the basis of host specificity, there was no reason to place these strains in one group or to separate them from the strains placed in group 5, which includes several isolates from the same or related hosts.

Group 5. Group 5 does not necessarily represent a genetic group, but it contains strains of fast-growing rhizobia that did not fall into any of the above-mentioned groups. All of these strains showed significantly less than $40 \%$ homology with any of the seven reference DNAs. One strain (Vr5) showed homologies with group 1 reference DNAs from NU125, CC275e, and NZP5459, which indicated some genetic relationship with this group. This strain was not placed in group 1 because group 2 strains which showed the same or higher homology values with group 1 reference DNAs were identified as a distinct genetic group with reference DNA from strain CC401. Similarly, strains J2040, $3 \mathrm{~F} 6 \mathrm{~S} 1$, and $\mathrm{CB} 81$ were placed in group 5 even though they showed greater similarity to the two Lotus reference strains than to the other five reference strains. From these examples it is seen that some strains with intermediate homology values cannot be clearly placed in any particular group. Such strains might be classified more accurately if homology values were obtained with additional reference DNAs.

The Rhizobium strain NZP5355 obtained from Robinia pseudoacacia and placed in group 5 differed from all of the other strains studied as it showed moderate (39\%) DNA homology with NZP5459 and CC811 reference strains and low values $(<11 \%)$ with the remaining reference strains. The other Rhizobium strain, NZP5302, taken from Robinia pseudoacacia was a typical group 4 strain since it showed 47 and $51 \%$ homologies with the two Lotus sp. reference DNAs and a low value (15\%) with DNA and NZP5459. Both strains were found to nodulate Robina pseudoacacia only.

Group 6. All of the nine slow-growing strains listed in Table 2 showed low DNA homology $(<10 \%)$ with all seven fast-growing reference 
strains. This result supports the generally recognized distinction between fast- and slow-growing rhizobia, but gives no indication of the genetic relationships among slow-growing rhizobia.

Reciprocal matches and genome sizes. The values for the reciprocal matches which can be extracted from Table 2 give a mean error of $\pm 1.4 \%$ with the greatest error being $\pm 4 \%$ for strains CC401 and SU47. Genome sizes were measured for reference strains CC275e, CC811, CC809a, and SU47. The respective values were $3.14 \times 10^{9}, 3.54 \times 10^{9}, 3.14 \times 10^{9}$ and $3.31 \times 10^{9}$ daltons with a mean of $3.28 \times 10^{9}$ daltons. The narrow range of genome sizes and the small error between reciprocal matches suggest that the homology values can be taken as a direct indication of shared similar cistrons.

Relationships between groups 1 through 4 and 6 (Table 2) are summarized in Fig. 1 by using the mean homologies between groups to construct a dendrogram.

Group 6 contains slow-growing rhizobia whose mean homology with all reference DNAs was $4 \%$. Consequently it is joined to the fast-growing rhizobia at that level.

The mean homologies between groups 4 and 1,4 and 3 , and 1 and 3 were 8,10 , and $14 \%$, respectively. The mean homologies between the first two groups were not significantly different and were lower than that between groups 1 and 3. Accordingly, the dendrogram shows group 4 branching from the remaining strains at $9 \%$ and group 3 branching from the remainder at $14 \%$.

The mean homologies between groups 4 and 1,3 and 2 , and 1 and 2 were $5,15,24 \%$, respectively. Consequently, group 2 branches from group 1 at $24 \%$.
Within group 1, Rhizobium leguminosarum strains were assigned to the same cluster as temperate zone clovers because of their similar homology patterns. Trifolium polymorphum rhizobia and Rhizobium phaseoli had mean homologies with reference strains CC275e, NU125, and NZP5459, from within their cluster, of 79 , 83 , and $58 \%$, respectively, whereas the mean intercluster homology was $50 \%$. DNA from some bean rhizobia has considerable homology with DNA from Trifolium polymorphum rhizobia, and therefore these groups were placed in the same cluster; however, it must be recognized that rhizobia which nodulate beans are a genetically diverse group. The mean homologies of African rhizobia with reference strains CC275e, NU125, and NZP5459 were 55, 52, and 57\%, respectively. Consequently, they were included in group 1 but were not assigned to either cluster.

\section{DISCUSSION}

The strains whose properties are described in this paper were selected to confirm and extend results reported in a previous communication (15). That paper described relationships among strains of Rhizobium trifolii and between $R$ hizobium trifolii and several strains of Rhizobium leguminosarum and Rhizobium phaseoli. Considerable genetic homology was reported within Rhizobium trifolii and between Rhizobium trifolii and Rhizobium leguminosarum, but rhizobia from Trifolium lupinaster, Trifolium semipilosum, and Phaseolus vulgaris showed less homology with the remaining clover rhizobia.

Homology among strains of Rhizobium trifolii. In this study, 33 Rhizobium strains from

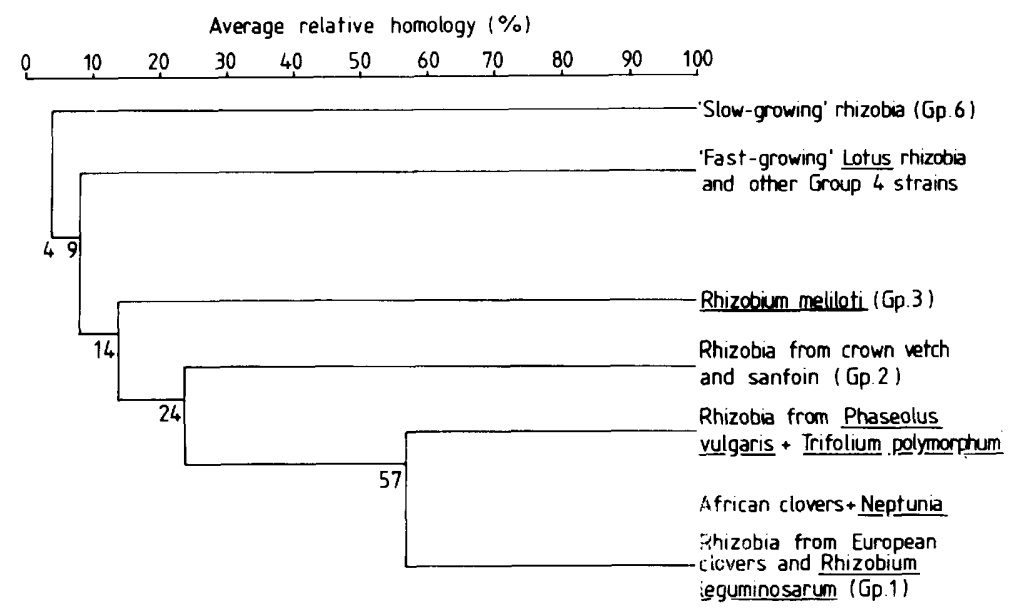

FIG. 1. Genetic relationship of Rhizobium strains described in this paper. 
Trifolium sp., including 21 strains not used previously, were examined to see if DNA homology was correlated with plant or geographic origin. The Rhizobium strains from European and Caucasian clovers all had similar homologies with reference strains NU125, CC275e, and NZP5459, and this confirms the earlier observation (15) made with different Rhizobium strains from similar plant origins. Three Rhizobium strains from indigenous North American Trifolium species were tested, and these showed similar homologies to those of Rhizobium strains associated with European clovers, except for the comparatively low homology of the strain from Trifolium carolinianum with CC275e DNA. It would be necessary to test a number of additional Rhizobium strains isolated from indigenous North American clovers in undisturbed natural habitats to determine whether this last result indicated that there is a genetically distinct subgroup among rhizobia associated with certain of these clovers.

The mean DNA homologies of the eight Rhizobium strains from African Trifolium spp. with reference DNA from NU125, CC275e, and NZP5459, although somewhat depressed by the low values for CB727, do support the proprosal that rhizobia from African clovers are genetically distinguishable from temperate-zone clover rhizobia (15). This proposition is in agreement with cross-inoculation information in which the distinction is more marked.

The mean DNA homologies for the four strains from the South American clover Trifolium polymorphum show that these are also genetically distinct. These strains had been obtained on three separate occasions from two different localities, all from unimproved pasture on virgin soil. One of the strains was found to fix some nitrogen on white and subterranean clovers (Table 1), but, nevertheless, DNA homology showed that it was related to the other strains from Trifolium polymorphum rather than to strains effective on white or subterranean clover. It seems possible that genes conferring the ability to fix nitrogen on European clovers may have been transferred naturally from introduced Rhizobium trifolii strains to this strain associated with Trifolium polymorphum.

Rhizobia from Trifolium lupinaster were reported to have a low homology with temperatezone clover and with bean rhizobia (15). DNA reassociation studies with additional reference strains confirmed this observation (Table 2) and showed that these rhizobia had considerably greater homology with fast-growing Lotus rhizobia (Group 4) than with reference strains taken from Trifolium sp. With the acquisition from Moscow of a few seeds of Trifolium lupinaster, it was possible to confirm that these strains could fix nitrogen on this clover. Thus, the strains undoubtedly belong to Rhizobium trifolii, as presently defined, although a recent observation that the strains could fix nitrogen on Sophora flavescens may indicate that their plant specificity differs markedly from that of most other Rhizobium trifolii strains. A strain from Sophora angustifolia (often classified as a subspecies or variety of $S$. flavescens) did not nodulate Trifolium lupinaster; however, strain J20400 from Caragana chamlagu was found to nodulate and fix nitrogen on one of three seedlings of Trifolium lupinaster, indicating that Trifolium lupinaster may be anomalous in its strain specificity. The natural range of Trifolium lupinaster extends westward from Japan across northern Asia into eastern Europe, and it would be valuable to determine whether isolates from Trifolium lupinaster in Poland or Czechoslovakia at the western end of its natural range are similar in DNA homology and plant specificity to the Japanese strains or show a closer relationship with strains associated with other European clovers.

DNA homology between Rhizobium trifolii and Rhizobium leguminosarum. The mean DNA homologies between rhizobia from several species of Lathyrus, Vicia, and Pisum and reference strains NU125, CC275e, and NZP5459 ('Table 2) were 50, 71, and 53\%, respectively. These values are very similar to those observed with European, Caucasian, and North American clovers. They confirm the earlier observation of relationship based on the homology of four strains of pea rhizobia with clover rhizobia (15) and extend it to rhizobia from a wider range of host plants in the Rhizobium leguminosarum cross-inoculation group. All strains were, however, from host species of European origin except Lathyrus japonicus, which, in its various forms, occurs also in European and Eastern Asia. It would be interesting to know whether rhizobia associated with species of $\mathrm{Vi}$ cia and Lathyrus from South America and species of these genera confined to eastern Asia would show homologies similar to those of strains from Trifolium polymorphum and Trifolium lupinaster, respectively.

DNA homology between Rhizobium trifolii and Rhizobium phaseoli. Rhizobium phaseoli is here restricted to those strains isolated from Phaseolus vulgaris, and it does not include the other strains listed in Table 1 as able to nodulate Phaseolus vulgaris. DNA from Rhizobium phaseoli strains showed moderate to low 
homology (mean $46 \%$ ) with reference DNA from Rhizobium trifolii strain CC275e. This lack of close homology between Rhizobium phaseoli strains and rhizobia (Rhizobium trifolii) from temperate-zone clovers was first reported by Gibbins and Gregory (7) and subsequently by Jarvis et al. (15). The mean homology with DNA from reference strain NU125 was slightly higher (49\%), and a few strains, particularly NZP5459, showed relatively high homology with this reference strain. The genetic diversity of the $R h i$ zobium phaseoli strains is also evident from the comparison of genetic homologies between the Rhizobium phaseoli reference DNA (NZP5459), other strains of Rhizobium phaseoli, and strains of Rhizobium trifolii and Rhizobium leguminosarum in group 1 . The mean homology of Rhizobium phaseoli strains (58\%) was not significantly greater than that of Rhizobium trifolii strains (54\%) or Rhizobium leguminosarum strains (53\%). It is concluded that Rhizobium phaseoli strains do not represent a sufficiently distinct genetic population to be designated as a separate species. In the future, it may be possible to resolve them into distinct genetic groups. For the present we believe they should be combined with Rhizobium trifolii and Rhizobium leguminosarum to form one species of fast-growing rhizobia designated Rhizobium leguminosarum Frank. If this is accepted, the homology between rhizobia from temperate-zone pasture clovers, from African clovers, and from Trifolium poly. morphum is such that they must also be included in this species. Consolidation of Rhizobium trifolii, Rhizobium leguminosarum, and Rhizobium phaseoli as one species was first recommended by Graham (9) after an examination of 100 strains of Rhizobium by numerical taxonomy.

DNA homology between consolidated Rhizobium leguminosarum and Rhizobium meliloti. The average DNA homologies of seven Rhizobium strains from Medicago sp. and Trigonella suavissima with the Rhizobium leguminosarum reference strains NU125, CC275e, and NZP5459 were 13,16 , and $12 \%$, respectively. Conversely, the Rhizobium meliloti reference strain SU47 had an average homology with the consolidated Rhizobium leguminosarum strains of $14 \%$. In addition, the homology of Rhizobium meliloti strains with respect to SU47 was much greater than that of Rhizobium leguminosarum with any of the reference strains we have used. It is concluded that Rhizobium meliloti is a separate, homogenous group. This view is supported by several independent studies $(9,16,23$, $24,27,28$ ) and contrasts with a report (7) that two strains of Rhizobium phaseoli were more closely related to Rhizobium meliloti than to Rhizobium leguminosarum. The genetic variability we have found among strains designated as Rhizobium phaseoli is a possible explanation for this observation, but our experience suggests that extensive homology between strains designated Rhizobium phaseoli and Rhizobium meliloti is uncommon.

DNA homology between a consolidated Rhizobium leguminosarum, Rhizobium meliloti, and Lotus sp. rhizobia. Little homology was shown between the DNA of fastgrowing rhizobia from Lotus sp. (CC811 and CC809a) used as reference strains and DNA from strains of a consolidated Rhizobium leg. uminosarum (group 1) or Rhizobium meliloti (group 3). Similarly, there was little homology between DNA from strains in group 4 and reference DNAs from strains CC275e, NU125, NZP5459, and SU47. These results confirm and extend the earlier report (16) which indicated a lack of homology between rhizobia from Lotus sp., Carmichaelia sp., and two strains of clover rhizobia. Group 4 includes rhizobia from 12 genera of host plants to which can be added Carmichaelia sp. and Clianthus puniceus (16). The existence of a widely branched cross-inoculation group containing species from at least nine plant genera was reported by Jensen (17). Group 4 contains rhizobia from several of the plant hosts mentioned by Jensen and provides evidence for the existence of a corresponding bacterial homology group among the fast-growing rhizobia. Clearly, this genetic group cannot be characterized by its plant specificity. At present it can only be recognized by DNA reassociation.

In an earlier study (16) the mean homology of nine Rhizobium strains from Carmichaelia sp. and Clianthus puniceus with reference strains CC811 was reported as $62 \%$. This was only slightly increased (to 65\%) when one of the strains from Carmichaelia spp. (NZP5105) was used as the reference strain. Such a moderate level of homology among strains obtained in a country as geographically isolated as New Zealand with a limited leguminous flora (most species of which are confined to these islands [13]), suggest that some genetic diversity is inherent among group 4 strains. If this is the case, it is unlikely that group 4 contains subgroups with mean homologies as high as those found in the consolidated species Rhizobium leguminosarum (group 1).

DNA homology between named species and previously unclassified strains. Two strains of rhizobia from Neptunia gracilis showed homologies with reference DNAs from strains in group 1 (Table 2), which suggested 
that they should be included in a consolidated Rhizobium leguminosarum. It should be noted that only two strains from Neptunia gracilis have been studied compared with the large number of strains derived from clovers, peas, and beans. Classifying these Neptunia strains with group 1 does not imply that all other strains from Neptunia sp. will be genetically homologous with group 1 rhizobia.

The six strains comprising group 2 are closely similar genetically and in plant specificity, although they were isolated from four different hosts. It remains to be seen whether the present clear demarcation of this group is maintained in the future when the DNA homologies and plant specificities of further strains isolated from the same and other hosts have been determined. Although all strains fixed nitrogen with both Leucaena leucocephala and Phaseolus vulgaris, they were very different from typical strains isolated from either of these hosts, both in DNA homology and in plant specificity. One further strain, taken from Onobrychis viciifolia (3G2c2a) and which differed in plant specificity from the group 2 strains, showed very low homology with the reference strain CC401; strains from other Sophora sp. were also very distinct. To confirm this, it would be necessary to test strains of European origin isolated from Coronilla and Onobrychis sp. Neither genus is indigenous to North America (13), but a related genus, Hedysarum, does have some North American species.

The 11 group 5 strains showed little DNA homology with any of the reference strains, although 6 of the 11 strains were from plant species which also gave strains included in group 4. Six of the group 5 strains, were isolated from tropical or subtropical localities, and this could indicate that further groups may exist among the little known fast-growing rhizobia from the tropics. Whether these tropical fast-growing strains showed any greater homology with slowgrowing strains of group 6 than to the strains in groups 1 to 4 remains to be determined.

The distinction between fast and slowgrowing rhizobia. The division of Rhizobium into two groups characterized as fast growers and slow growers is well established $(2,10,18$, $20,22,26,27)$. It has been proposed that the difference between these groups is large enough to justify splitting the rhizobia into two genera, Rhizobium and Phytomyxa $(9,21,26)$. Counter arguments, seeking to retain one genus for all legume root-nodule bacteria, center on the lack of information about slow-growers $(2,24)$ or on the guanine-plus-cytosine contents of the DNA and flagellation in strains which infect lupins
(Rhizobium lupini), soya beans (Rhizobium japonicum), or cowpeas (5). The slow-growing rhizobia described in this paper each had a mean homology of $10 \%$ or less with the seven fastgrowing reference strains used. This low-level homology with fast-growing rhizobia strongly supports a division of root bacteria into two related genera. It also indicates a measure of relationship which is inconsistent with the proposition that fast-growing and slow-growing rhizobia should be placed in different taxonomic orders (26).

Our results suggest that the fast-growing rhizobia can be classified into four species corresponding with the four genetic groups we have identified: group 1 comprises Rhizobium trifolii, Rhizobium leguminosarum, and Rhizobium phaseoli, all consolidated under the name $R h i$ zobium leguminosarum; group 2 comprises the Rhizobium strains from Coronilla sp. and some strains from Sophora and Onobrychis sp.; group 3 comprises Rhizobium meliloti; and group 4 comprises strains from a variety of hosts including Lotus corniculatus, Lotus tenuis, and Lupinus densiflorus. Some of the previously unclassifed rhizobia (group 5) do not show close homology with any of the reference strains we have used, and it is probable that further genetic groups of fast-growing rhizobia remain to be identified.

\section{ACKNOWLEDGMENTS}

We thank the following for the supply of Rhizobium strains (strains supplied within parentheses): L. Bordeleau (Balsac), J. Brockwell (CC227, CC229, CC231a, CC2093, CC2017, CC811, CC809a, CC1005), J. C. Burton (92AA1, 92AA3, 31A5, 146B2, 146A1), B. E. Caldwell (3D1j12, 3D1j14, 3HOc3, 3HOg2, 3HOg1), C. E. Clapp (3DOa13), K. W. Clark (V73M5), H. D. L. Corby (674A, 408A), R. A. Date (CB758, CB774, CB775, CB778, SU391, TA101, CC511, 116A5, SU343, CB2919, CB81, NGR8, 27A5, Revadim), J. Dobereiner (A1, F3, F300, F310, ES1, Vr5, X18b, 4001), P. H. Graham (CIAT75, CIAT137, CIAT161, CIAT225, CIAT632), A. Hastings (CC275e, SU47, CB1170, U45), B. Humphrey (NU125, NU126, NU132, NU134), G. Ishizawa (J2061, J1010, J2040), the late H. L. Jensen (Ca.Wisc, L.c.265DA, L.densif85), the late D. O. Norris (CB727, CB596, 3HOc3, CB971, CB2001, CB2002, 3HOal, CB1274, CB362, CB712), P. S. Nutman (3644), C. A. Parker (SU202, WU290, WU351, WU425), E. B. Roslycky (39, 41, 52, 63, 94, 100), R. J. Roughley (CC2480a), B. W. Strijdom (SA3), G. G. Taylor (461), J. A. Thompson (CC401, 116A14), I. Watenabe (TL3, TLN3), and D. F. Weber (3F6s1, 3G2c2a). We also thank L. D. Kennedy for growth-rate measurements, and R. R. Hidajat and C. P. Liddane for technical assistance.

We thank the Department of Scientific and Industrial Research and the University Grants Committee, New Zealand, for financial support.

\section{REPRINT REQUESTS}

Address reprint requests to: Dr. B. D. W. Jarvis, Department of Microbiology and Genetics, Massey University, Palmerston North, New Zealand. 


\section{LITERATURE CITED}

1. Brockwell, J., and F. W. Hely. 1966. Symbiotic characteristics of Rhizobium meliloti: an appraisal of the systematic treatment of nodulation and nitrogen fixation interactions between hosts and rhizobia of diverse origins. Aust. J. Agric. Res. 17:885-899.

2. De Ley, J. 1968. DNA base composition and hybridization in the taxonomy of phytopathogenic bacteria. Annu. Rev. Phytopathol. 6:63-90.

3. De Ley J. 1971. The determination of the molecular weight of DNA per bacterial nucleoid, p. 301-309. In J. R. Norris and D. W. Ribbons (ed.), Methods in microbiology, vol. 5A. Academic Press, Inc., London.

4. De Ley, J., H. Cattoir, and A. Reynaerts. 1970. The quantitative measurement of DNA hybridization from renaturation rates. Eur. J. Biochem. 12:133-142.

5. De Ley, J., and A. Rassel. 1965. DNA base composition, flagellation and taxonomy of the genus Rhizobium. J Gen. Microbiol. 41:85-91.

6. Dixon, R. O. D. 1969. Rhizobia with particular reference to relationships with host plants. Annu. Rev. Microbiol. 23:137-158.

7. Gibbins, A. M., and K. F. Gregory. 1972. Relatedness among Rhizobium and Agrobacterium species determined by three methods of nucleic acid hybridization. J. Bacteriol. 111:129-141.

8. Gillis, M., J. De Ley, and M. De Cleene. 1970. The determination of molecular weight of bacterial genome DNA from renaturation rates. Eur. J. Biochem. 12:143153.

9. Graham, P. H. 1964. The application of computer techniques to the taxonomy of the root nodule bacteria of legumes. J. Gen. Microbiol. 35:511-517.

10. Graham, P. H. 1976. Identification and classification of root nodule bacteria, p. 99-112. In P. S. Nutman (ed.), Symbiotic nitrogen fixation in plants. Cambridge University Press, London.

11. Greenwood, R. M. 1978. Rhizobia associated with indigenous legumes of New Zealand and Lord Howe Island, p. 402-403 In M. W. Loutit and J. A. R. Miles (ed.), Microbial ecology. Springer-Verlag, Berlin.

12. Heberlein, G. T., J. De Ley, and R. Tijtgat. 1967. Deoxyribonucleic acid homology and taxonomy of Agrobacterium, Rhizobium, and Chromobacterium. J. Bacteriol. 94:116-124.

13. Hutchinson, J. 1964. The genera of flowering plants. Clarendon Press, Oxford.

14. Ishizawa, S. 1954. Studies on the root-nodule bacteria of leguminous plants. Part II. The relationship between nodule bacteria and leguminous plants. Part I. From the view of nodule production (a) cross-inoculation tests. J. Sci. Soil Manure (Jpn.) 24:297-302. (English summary.)

15. Jarvis, B. D. W., A. G. Dick, and R. M. Greenwood. 1980. Deoxyribonucleic acid homology among strains of Rhizobium trifolii and related species. Int. J. Syst. Bacteriol. 30:42-52.

16. Jarvis, B. D. W., T. S. Maclean, I. G. C. Robertson, and G. R. Fanning. 1977. Phenetic similarity and DNA base sequence homology of root nodule bacteria from New Zealand native legumes and Rhizobium strains from agricultural plants. N.Z. J. Agric. Res. 20:235-248.

17. Jensen, H. L., and Anna-Lise Hansen. 1968. Observations on host plant relations in root nodule bacteria of the Lotus-Anthyllis and the Lupinus-Ornithopus groups. Acta Agric. Scand. 18:135-142.

18. Jordan, D. C., and O. N. Allen. 1974. Family III. $R h i$ zobiaceae Conn 1938. In R. E. Buchanan and N. E. Gibbons (ed.), Bergey's manual of determinative bacteriology, 8th ed. The Williams \& Wilkins Co., Baltimore.

19. Keele, B. B. Jr., P. B. Hamilton, and G. H. Elkan. 1969. Glucose catabolism in Rhizobium japonicum. J. Bacteriol. 97:1184-1191.

20. Mackenzie, S. L., M. S. Lapp, and J. J. Child. 1979. Fatty acid composition of Rhizobium spp. Can. J. Microbiol. 25:68-74.

21. Moffett, M. L., and R. R. Colwell. 1968. Adansonian analysis of the Rhizobiaceae. J. Gen. Microbiol. 51: 245-266.

22. Norris, D. O. 1965. Acid production by Rhizobium, a unifying concept. Plant Soil 22:143-166.

23. Staniewski, R. 1970. Relationship among different $R h i$ zobium strains determined by phage lysis. Acta. Microbiol. Pol. Ser. B. 2:3-11.

24. t'Mannetje, L. 1967. A re-examination of the taxonomy of the genus Rhizobium and related genera using numerical analysis. Antonie van Leeuwenhoek J. Microbiol. Serol. 33:477-491.

25. Trinick, M. J. 1965. Medicago sativa nodulation with Leucaena leucocephala root-nodule bacteria. Aust. J. Sci. 27:263-264.

26. Vincent, J. M. 1977. Rhizobium: general microbiology, p. 277-366. In R. W. F. Hardy and W. S. Silver (ed.), A treatise on dinitrogen fixation. John Wiley \& Sons, Inc., New York.

27. Vincent, J. M., and B. Humphrey. 1970. Taxonomically significant group antigens in Rhizobium. J. Gen. Microbiol. 63:379-382.

28. White, L. O. 1972. The taxonomy of the crown-gall organism Agrobacterium tumefaciens and its relationship to rhizobia and other agrobacteria. J. Gen. Microbiol. 72:565-574. 